\title{
Health care students' needs on stress management and emotional intelligence
}

\author{
Eirini Florou and Evangelos C. Alexopoulos* \\ School of Social Sciences, Hellenic Open University, Patras, Greece
}

\begin{abstract}
Objective: to evaluate the levels of stress, anxiety, depression and emotional intelligence in students and to explore the possible impact of specific courses.

Subjects and methods: 270 health care students (social workers \& nurses) and 275 non-health care students (engineers \& technologists) provided relative data by answering the Wong Law Emotional Intelligence Scale, DASS21 and PSS-14.

Results: All students scored higher in "others emotion appraisal" and lower in "regulation of emotions" subscale of emotional intelligence (EI). Health care students (HCS) scored higher in both EI subscales compared to others but they also reported higher levels of depression, stress and anxiety (especially the social workers). EI score did not differ significantly by seniority level while only senior nursing students reported lower levels of anxiety and stress. EI score was related to perceived stress, depression and gender. Completion of courses enhancing "empathy" was related to less perceived stress in senior social work students.
\end{abstract}

Conclusion: Our results highlight the need of comprehensive and combined educational curricula on emotional intelligence and stress management in HCS.

\section{Introduction}

Emotional intelligence (EI) is an ongoing process in human life during which we learn to manage and express our emotions in an appropriate manner, in the appropriate place and time, to smooth coexistence of people to achieve a common objective; Goleman named the development of EI as maturity [1]. EI consists of mental and emotional abilities and skills that enable humans to perceive and manage their own and the others' emotional states, in a process of personal and social development [2]. Research on EI primarily focus on the cognitive procedure (capacity or skills models) [3] or on personality characteristics and social skills (mixed models) $[1,4,5]$.

Health care workers are expected to develop high EI to copy with high psychological demands of their job as an essential skill for practice. Social workers and community nurses who support handicapped individuals and groups, prevent and manage social problems and help in social health policy planning need these skills that enable them to manage individual and group problems, many time under stressful events or states (wars, urbanization, industrialization) [6]. These skills include, but not limited to, communication, active and supportive listening and empathy that constitute basic features of emotional intelligence. Studies on emotional intelligence in social workers and community nurses are few and contradictory, but most have reported moderate levels of EI $[4,7,8]$.

This research aims to explore the levels and the interrelations of stress, anxiety, depression and emotional intelligence in higher education students and to explore the possible impact of specific "empathy" courses in social work students.

\section{Methods}

\section{Participants and study design}

Participants were randomly selected from students of the first and last years of the Schools of Health and Welfare Services (Social
Work and Nursing Departments), the Schools of Agricultural and Food Technology (Department of Agricultural Technology) and the Schools of Engineering (Department of Informatics Engineering). The selection of the specific departments was based on the consideration that students of social work and nursing might differ from the other departments' students as the orientation of their studies do focus on direct human communication and care.

After receiving the approval from the Ethics Committee of the Higher Technological Educational Institute of Crete, in the first semester of 2015, the Head of each department was asked to provide access during one randomly selected obligatory course of the first and the last year students. During these courses, all enrolled students should be present. The self -completed anonymous questionnaires were distributed and collected in classroom by a member of the research team (EF). The participants completed voluntarily the questionnaire and specific instructions were provided to avoid misunderstandings.

\section{Measures}

The wong law emotional intelligence scale: For measuring emotional intelligence the Wong Law Emotional Intelligence Scale (WLEIS) was used [9]. The scale consists of four dimensions that are consistent with Mayer and Salovey's (1997) definition of EI. The Self-Emotion Appraisal (SEA) dimension assesses an individual's selfperceived ability to understand their emotions. The Others' Emotion

Correspondence to: Evangelos C. Alexopoulos, School of Social Sciences, Hellenic Open University, Patras, Greece, E-mail: ecalexop@med.uoa.gr

Key words: higher education, human recourses, occupational health and wellbeing, stress management, emotional intelligence, social work, nurse, students, health care workers

Received: July 10, 2017; Accepted: August 08, 2017; Published: August 11, 2017 
Appraisal (OEA) dimension assesses a person's tendency to be able to perceive other peoples' emotions. The Use of Emotion (UOE) dimension concerns the self-perceived tendency to motivate oneself to enhance performance. The Regulation of Emotion (ROE) dimension concerns individuals' perceived ability to regulate their own emotions. The questionnaire has been validated in Greek language [10]. In our study Cronbach alphas for the four subscales were well above 0,7 (SEA $=0,728, \mathrm{OEA}=0,712, \mathrm{UOE}=0,758, \mathrm{ROE}=0,787)$.

The depression, anxiety and stress scale: For measuring the negative feelings of anxiety, depression and stress we have used the DASS 21 Scale (Depression, Anxiety and Stress Scale) [11]. The scale consists of three dimensions, each includes seven questions and likert type answers ranged as follows: 0 (not applies to me) to 3 (applies to me too much or most of the time). We used the validated Greek version of the questionnaire [12] and we found very high Cronbach alphas (Anxiety=0,898, Depression=0,909 and Stress $=0,906$ ).

The perceived stress scale: For measuring Perceived Stress we used the Perceived Stress Scale [13]. PSS Scale consists of 14 questions that assess the perception of stressful experiences by asking the respondent to rate the frequency of certain emotions and thoughts that were created under certain circumstances in the previous month. We used the validated Greek version of the questionnaire [14]. The Cronbach alpha for the PSS Scale was 0,735 .

\section{Statistical analysis}

Frequency distributions or means and SD were calculated for the descriptive characteristics of participating students, as appropriate. All scores of the subscales and scales of the Wong Law Emotional Intelligence Scale, the Depression, Anxiety and Stress scale and the Perceived Stress Scale were tested for normality and appropriate tests were implemented after their modification $(\log 10)$, if it was needed. For the scoring of the Wong Law EI subscales the average instead of the sum of the likert-scale answers was used (is one of the two options available) [10]. Relations among variables were tested either by the nonparametric Kruskal Wallis, chi square, or by Spearman tests as appropriate. Multiple linear regression of each scale separately took place. Level of significance was set to 0.05 without further correction (e.g. bonferroni) for multiple comparisons, as it was not deem necessary. To test if the highest grading in the "empathy enhancing" Social Workers' courses (considered to enhance skills and communication) was associated with higher emotional intelligence, total cumulative score was dichotomized to the 50th percentile (median). Three categories were formed with those above median (33 students), below median $(n=32)$ and all the rest $(n=66)$ who failed or were not tested in at least one of these courses. IBM SPSS 22.0 statistical program was employed for all analyses.

\section{Results}

In total 545 students participated with a mean age of 21,9 years. $43,1 \%$ were males and $56,3 \%$ attended the 6 th semester (seniors). $24,2 \%$ were students of the Department of Social Work, 25,3\% of the Nursing Department and 50,5\% of other Departments (Table 1). Mean scores of the WLEIS, DASS21 and PSS scales among first year and senior students are shown in Table 2.

There were not significant differences of Emotional Intelligence (EI) between the two semesters in any of the departments (Table 2). First year students of Nursing department, in relation to their senior colleagues, have a significantly higher average rating in the Anxiety dimension of DASS $21(12,1$ versus $8.8, \mathrm{p}=0.009)$, in the Stress dimension of DASS21 (16,1 versus $14,3, \mathrm{p}=0,072)$, as well as in the PSS-14 (26,3 versus 23.3, $\mathrm{p}=0.031)$.
Table 1. Descriptive characteristics of the 545 participants

\begin{tabular}{|l|l|l|}
\hline \multicolumn{1}{|l|}{} & N & \% \\
\hline Males & 235 & 43,1 \\
\hline Females & 310 & 56,9 \\
\hline Age group & & \\
\hline $19-20$ years & 181 & 34,0 \\
\hline $21-22$ & 214 & 40,2 \\
\hline $23-25$ & 100 & 18,8 \\
\hline $26+$ & 38 & 7,1 \\
\hline Study semester & & \\
\hline $2^{\text {nd }}$ & 238 & 43,7 \\
\hline $6^{\text {th }}$ & 307 & 56,3 \\
\hline Department of study & & \\
\hline Social Work & 132 & 24,2 \\
\hline Nursing & 138 & 25,3 \\
\hline Other schools/Departments* & 275 & 50,5 \\
\hline Marital status & & \\
\hline Single & 523 & 96,3 \\
\hline Married & 12 & 2,2 \\
\hline Divorced & 7 & 1,3 \\
\hline Widow/er & 1 & 0,2 \\
\hline Children & 15 & 2,8 \\
\hline Cohabitation Status & & 32,6 \\
\hline Cohabits & 176 & 67,4 \\
\hline Living alone & 364 & \\
\hline Depatis & & \\
\hline
\end{tabular}

*Departments of Agricultural Technology, Informatics and Electrical Engineering.

Most differences between WLEIS, DASS21 AND PSS14 scores of students of the same semester between schools were again not statistically significant (Table 3 ). First year nursing students exhibited a significantly higher average rating compared to those of the Department of Social Work or other departments of the EI dimension of "Others' Emotion Appraisal” (5,4 from 5.2 and 4.9, respectively, $\mathrm{p}=0.009$ ). Students of Social Work had a significantly higher (unfavorable) score in "Depression" (15,6 versus 13.2 and $11.2, \mathrm{p}=0.031)$ and "Stress" $(18,8$ versus 16.1 and $14.7, \mathrm{p}=0.039)$. Last year Social Work students also reported significantly more stress both in DASS-21 $(18,4$ versus 14.3 and $14.6, \mathrm{p}=0.005)$ and in PSS-14 (27,1 versus 23.3 and 26.5, $\mathrm{p}<0.001$ ) (Table 3).

The possible relation of parental occupation with student score in WLEIS, DASS21 \& PSS14, was evaluated but no statistically significant differences were found. However, students whose father occupation belong to arm forces or pilots had higher average rating in the "Others' Emotional Appraisal" of WLEIS, (5,8 vs 5,1 for "manual workers", 5,2 for "freelancers", 5,0 for "office employees and professionals" and 5,0 for "retirees, unemployed, household, departed", p=0,0061).

In multiple linear regression, gender and perceived stress were significantly related to "Others' Emotion Appraisal" ( $b=0,200$ and $b=$ -0.109 , respectively) (Table 4 ). Perceived stress was also significantly related to "Self Emotion Appraisal" ( $b=-0.244, \mathrm{p}<0.001)$, to the "Use of emotion" ( $b=-0.309, \mathrm{p}<0.001)$ and the "Regulation of Emotion" $(\mathrm{b}=-0.369, \mathrm{p}<0.001)$ (Table 4). Depression also exhibited negative relation on the "Use of emotion" ( $b=-0.237, \mathrm{p}<0.001)$ as does Stress on "Regulation of emotion" ( $b=-0.229, \mathrm{p}<0.001)$.

In multiple linear regression DASS21 subscales, perceived stress score (of PSS-14) was significantly related to depression score (b = $0.466, \mathrm{p}<0.001)$ and anxiety score $(\mathrm{b}=0.422, \mathrm{p}<0.001)$. The department (Social Work and/or nursing) preserve its univariate associations both with "Depression" $(\mathrm{b}=-0.093, \mathrm{p}=0.029)$ and «Stress» $(\mathrm{b}=-0.104, \mathrm{p}=$ 0.018). Women reported more stress $(b=0.095, p=0.033)$. 
Table 2. Descriptives of mean scores (SD) in WLEIS, DASS21 and PSS-14 questionnaires per school and semester

\begin{tabular}{|c|c|c|c|c|c|c|c|c|c|}
\hline & \multicolumn{3}{|c|}{ All students } & \multicolumn{2}{|c|}{ Social Work } & \multicolumn{2}{|c|}{ Nursing Department } & \multicolumn{2}{|c|}{ other departments* } \\
\hline & $\mathrm{N}=545$ & $\begin{array}{l}\text { 2nd } \\
\mathrm{N}=238\end{array}$ & $\begin{array}{l}\text { 6th } \\
N=307\end{array}$ & $\begin{array}{l}\text { 2nd } \\
\mathrm{N}=62\end{array}$ & $\begin{array}{l}\text { 6th } \\
\mathrm{N}=70\end{array}$ & $\begin{array}{l}\text { 2nd } \\
N=68\end{array}$ & $\begin{array}{l}6 \text { th } \\
N==70\end{array}$ & $\begin{array}{l}\text { 2nd } \\
\mathrm{N}=108\end{array}$ & $\begin{array}{l}\text { 6th } \\
N=167\end{array}$ \\
\hline \multicolumn{10}{|l|}{$\begin{array}{l}\text { Wong Law Emotional } \\
\text { Intelligent }\end{array}$} \\
\hline Self- Emotion Appraisal & $5,0(1,1)$ & $4,9(1,1)$ & $5,0(1,1)$ & $5,0(1,0)$ & $5,1(0,9)$ & $5,0(1,1)$ & $5,1(1,3)$ & $4,9(1,2)$ & $4,9(1,2)$ \\
\hline Others' Emotion Appraisal & $5,1(1,1)$ & $5,1(1,1)$ & $5,0(1,1)$ & $5,2(0,9)$ & $5,2(0,9)$ & $5,4(1,0)$ & $5,2(1,1)$ & $4,9(1,1)$ & $4,9(1,1)$ \\
\hline Use of Emotion & $4,7(1,2)$ & $4,7(1,2)$ & $4,8(1,2)$ & $4,7(1,1)$ & $4,6(1,1)$ & $4,8(1,2)$ & $5,1(1,3)$ & $4,6(1,2)$ & $4,8(1,2)$ \\
\hline Regulation of Emotion & $4,5(1,2)$ & $4,4(1,2)$ & $4,5(1,2)$ & $4,2(1,2)$ & $4,4(0,9)$ & $4,6(1,2)$ & $4,8(1,2)$ & $4,5(1,3)$ & $4,4(1,2)$ \\
\hline \multicolumn{10}{|l|}{ DASS21 } \\
\hline Depression & $12,3(10,0)$ & $13,0(10,4)$ & $11,9(9,7)$ & $15,6(10,8)$ & $14,4(11,3)$ & $13,2(10,2)$ & $10,0(8,7)$ & $11,2(10,0)$ & $11,6(9,3)$ \\
\hline Anxiety & $10,6(9,3)$ & $11,2(9,3)$ & $10,2(9,3)$ & $12,5(9,9)$ & $12,1(10,1)$ & $12,1(9,1)$ & $8,8(9,9)$ & $10,0(8,9)$ & $9,9(8,4)$ \\
\hline Stress & $15,7(9,3)$ & $16,2(9,4)$ & $15,4(9,2)$ & $18,8(10,0)$ & $18,4(8,5)$ & $16,1(7,9)$ & $14,3(9,3)$ & $14,7(9,6)$ & $14,6(9,2)$ \\
\hline PSS14 & $26,3(6,9)$ & $26,8(6,6)$ & $25,9(7,2)$ & $28,3(6,2)$ & $27,1(7,2)$ & $26,3(6,6)$ & $23,3(7,8)$ & $26,2(6,9)$ & $14,6(9,4)$ \\
\hline
\end{tabular}

In bold the significant differences; *Department of Informatics, Agricultural Technology and Electrical Engineering

Table 3. Comparisons of mean scores (SD) in WLEIS, DASS21 and PSS 14-questionnaire among schools per semester

\begin{tabular}{|c|c|c|c|c|c|c|c|c|}
\hline & \multicolumn{4}{|c|}{ First year students } & \multicolumn{4}{|l|}{ Senior students } \\
\hline & $\begin{array}{l}\text { Social Work, } \\
\mathrm{N}=62\end{array}$ & $\begin{array}{l}\text { Nursing, } \\
\mathrm{N}=68\end{array}$ & $\begin{array}{l}\text { Other } \\
\text { departments, } \\
\mathrm{N}=108\end{array}$ & & $\begin{array}{l}\text { Social Work, } \\
N=70\end{array}$ & $\begin{array}{l}\text { Nursing, } \\
\mathrm{N}=70\end{array}$ & $\begin{array}{l}\text { Other } \\
\text { departments, } \\
\mathrm{N}=167\end{array}$ & \\
\hline Scale & \multicolumn{3}{|c|}{ Average (standard deviation) } & p-value & & & & p-value \\
\hline \multicolumn{9}{|l|}{$\begin{array}{l}\text { Wong Law Emotional } \\
\text { Intelligence }\end{array}$} \\
\hline Self- Emotion Appraisal & $5,0(1,0)$ & $5,0(1,1)$ & $4,9(1,2)$ & 0,613 & $5,1(0,9)$ & $5,1(1,3)$ & $4,9(1,2)$ & 0,335 \\
\hline Others' Emotion Appraisal & $5,2(0,9)$ & $5,4(1,0)$ & $4,9(1,5)$ & 0,009 & $5,2(0,9)$ & $5,2(1,1)$ & $4,9(1,1)$ & 0,070 \\
\hline Use of Emotion & $4,7(1,1)$ & $4,8(1,2)$ & $4,6(1,2)$ & 0,423 & $4,6(1,1)$ & $5,1(1,3)$ & $4,8(1,2)$ & 0,196 \\
\hline Regulation of Emotion & $4,2(1,2)$ & $4,6(1,2)$ & $4,5(1,3)$ & 0,157 & $4,4(1,0)$ & $4,8(1,2)$ & $4,4(1,2)$ & 0,071 \\
\hline \multicolumn{9}{|l|}{ DASS21 } \\
\hline Depression & $15,6(10,8)$ & $13,2(10,2)$ & $11,2(10,0)$ & $\mathbf{0 , 0 3 1}$ & $14,4(11,3)$ & $10,0(8,7)$ & $11,6(9,3)$ & 0,113 \\
\hline Anxiety & $12,5(9,9)$ & $12,1(9,1)$ & $9,9(8,9)$ & 0,124 & $12,1(10,1)$ & $8,8(10,0)$ & $9,9(8,5)$ & 0,108 \\
\hline Stress & $18,8(9,9)$ & $16,1(7,9)$ & $14,7(9,6)$ & 0,039 & $18,4(8,4)$ & $14,3(9,3)$ & $14,6(9,2)$ & 0,005 \\
\hline PSS14 & $28,3(6,2)$ & $26,3(6,6)$ & $26,2(6,8)$ & 0,125 & $27,1(7,2)$ & $23,3(7,8)$ & $26,5(6,7)$ & $<0,001$ \\
\hline
\end{tabular}

Table 4. Multiple linear regression of Wong Law Emotional Intelligence SUBScales (WLEIS)

\begin{tabular}{|c|c|c|c|c|c|c|c|c|}
\hline \multirow[b]{2}{*}{ Prognostic factors } & \multicolumn{2}{|c|}{ Self Emotion Appraisal } & \multicolumn{2}{|c|}{ Others' Emotion Appraisal } & \multicolumn{2}{|c|}{ Use of Emotion } & \multicolumn{2}{|c|}{ Regulation of Emotion } \\
\hline & standardized beta & $\mathrm{p}$-value & stand. beta & $\mathrm{p}$ & stand. beta & $\mathrm{p}$ & stand. beta & $\mathrm{p}$ \\
\hline Gender & 0,068 & 0,163 & 0,200 & $<0,001$ & 0,073 & 0,115 & 0,002 & 0,965 \\
\hline Children & $-0,054$ & 0,206 & $-0,012$ & 0,775 & $-0,055$ & 0,175 & $-0,043$ & 0,291 \\
\hline Cohabitation Status & 0,017 & 0,687 & 0,007 & 0,869 & $-0,002$ & 0,967 & $-0,007$ & 0,857 \\
\hline Semester of study & $-0,003$ & 0,941 & $-0,031$ & 0,474 & 0,016 & 0,693 & 0,008 & 0,848 \\
\hline Department of study & $-0,052$ & 0,286 & $-0,041$ & 0,408 & $-0,002$ & 0,970 & $-0,032$ & 0,500 \\
\hline \multicolumn{9}{|l|}{ DASS21 } \\
\hline Depression & $-0,038$ & 0,557 & $-0,005$ & 0,935 & $-0,237$ & $<0,001$ & 0,074 & 0,229 \\
\hline Anxiety & $-0,042$ & 0,493 & 0,040 & 0,523 & $-0,006$ & 0,917 & 0,085 & 0,142 \\
\hline Stress & $-0,014$ & 0,827 & $-0,033$ & 0,614 & 0,087 & 0,150 & $-0,229$ & $<0,001$ \\
\hline PSS14 & $-0,244$ & $<0,001$ & $-0,109$ & 0,034 & $-0,309$ & $<\mathbf{0 , 0 0 1}$ & $-0,369$ & $<0,001$ \\
\hline
\end{tabular}

Values were $\log 10$ transformed. Reference values in categorical variables: (1:male, 2:female); if they have children (1:yes, 2:no); cohabitation status (1:cohabitates, 2:live alone); semester of study (1: first year, 2:senior); and department of study (1:social work, 2:nursing, 3:other departments).

In Table 5 the relation between successful completion in the empathy specific courses of social work students with the scores in WLEIS, DASS21 and PSS14 is shown. EI subscales scores did not differ between groups, however anxiety and mainly perceived stress was borderline significantly lower in successful students $(\mathrm{p}<0.10)$.

\section{Discussion}

This study provides comparative data on the level of emotional intelligence (EI) in higher education students and its relationship with the department of study, the semester, specific courses, stress and negative emotions and individual factors. All students scored higher in the subscale "others' emotion appraisal", and lower in the subscale "regulation of emotion". The seniority was not significantly related to emotional intelligence. Probably the small age difference excused this finding which is contradicted most research data on the increase of EI with age $[4,15]$. The academic performance in the "empathy enhancing" courses in social work department again was not found to be related to emotional intelligence although in that case the crossectional design of the study may hamper a positive impact and precludes valid inference [16]. Previous research findings have shown that there is no significant relationship between emotional intelligence and academic achievement [17]. In our case, financial crisis restraints like the loss of teachers (due 
Table 5. Comparison in WLEIS, DASS21 and PSS 14 in relation to successful completion of "empathy enhancing" courses fn social work students.

\begin{tabular}{|c|c|c|c|c|}
\hline & \multicolumn{3}{|c|}{$\begin{array}{l}\text { Cumulative score in "empathy } \\
\text { enhancing" courses of social work } \\
\text { department curriculum }\end{array}$} & \multirow{4}{*}{ p-value } \\
\hline & $\begin{array}{l}\text { Unsuccessful } \\
\text { or non- } \\
\text { participation } \\
\mathrm{N}=66\end{array}$ & $\begin{array}{l}\text { Success with } \\
\text { score below } \\
\text { median } \mathrm{N}=32\end{array}$ & $\begin{array}{l}\text { Success with } \\
\text { score above } \\
\text { median } \\
\mathrm{N}=33\end{array}$ & \\
\hline Scale & & & & \\
\hline \multicolumn{4}{|l|}{$\begin{array}{l}\text { Wong Law Emotional } \\
\text { Intelligence }\end{array}$} & \\
\hline Self emotion appraisal & $5,0(1,0)$ & $5,0(1,2)$ & $5,2(0,6)$ & 0,286 \\
\hline Others' emotion appraisal & $5,2(1,0)$ & $5,3(1,0)$ & $5,2(0,7)$ & 0,850 \\
\hline Use of emotion & $4,6(1,1)$ & $4,6(1,2)$ & $4,7(1,0)$ & 0,866 \\
\hline Regulation of emotion & $4,2(1,2)$ & $4,4(1,2)$ & $4,3(0,7)$ & 0,273 \\
\hline \multicolumn{5}{|l|}{ DASS21 } \\
\hline Depression & $16,3(11,3)$ & $14,2(11,9)$ & $13,4(9,5)$ & 0,536 \\
\hline Anxiety & $13,0(10,1)$ & $13,4(10,6)$ & $10,2(8,9)$ & 0,199 \\
\hline Stress & $19,0(10,1)$ & $19,7(8,4)$ & $17,2(7,9)$ & 0,994 \\
\hline PSS14 & $28,4(6,2)$ & $28,0(7,5)$ & $25,9(6,9)$ & 0,077 \\
\hline
\end{tabular}

to increased retirements and lack of new calls due to financial crisis) might have influenced the specific outcomes. On the other hand higher scores in specialty courses were found to be related to lower levels of perceived stress to social work students. We conclude that students having higher academic achievement are more likely to have high personal appreciation for their ability to express and manage feelings and thoughts that were created under certain stressful conditions.

Perceived stress was negatively related to "use of emotion", "regulation of emotion" and positively with "others emotion appraisal" to all students. Women scored higher in the "others' emotion appraisal" as in other studies $[4,18,19]$. This difference between men and women is common when the method of self -reports is used as a research tool $[20,21]$.

Social work students scored significantly higher in "depression" and "stress" compared to nursing and other school's students. The results are alarming and in accordance with previous findings of intense stress problems in social workers $[22,23]$. In addition, high levels of work disability have been monitored in social workers $[24,25]$ which may be considered as an indirect indication of a lack of appropriate training and education throughout the course of a social worker's career [26].

First year nursing students scored higher in "depression", "anxiety" and "stress" as well as in perceived stress compared with their senior colleagues. It seems that during their studies nurses develop better coping strategies and emotion regulation but perhaps the better employment opportunities may account for this favorable reduction.

The results of the present study should be interpreted in the light of several limitations. Firstly, data collected by the method of self-reports so the answers based on subjective assessments of the respondents. Therefore, factors such as psychological condition, intense of giving the socially acceptable answer and not personal, the influence of the other participants in research might have an impact. Secondly, the sample might not be representative of all enrolled students and thus corresponding schools in other areas. So, our results might not be equally valid for other students of similar schools e.g. social work students. It would be interesting a longitudinal study to follow the development of emotional intelligence. Furthermore, a possible effect of family-economic environment in study variables could not be excluded although different occupational categories of students' parents were evaluated and no effect found.

\section{Conclusions}

Emotional intelligence is an ongoing process of personal and social development and future health care workers and especially social workers and community nurses need a plethora of such skills. Our findings suggest that stress and anxiety in higher education students especially in the future health care professionals might hamper development of emotional intelligence. Furthermore, related courses curricula may be not successful to enhance these skills. Health profession students are intended to work with individuals, so they need to know the world of emotions, to be trained in the identification, expression and management of emotions. Therefore, it would of great value for the quality of care and their occupational health and wellbeing, the future social workers and nurses to be properly educated in "emotional intelligence development" and "stress management".

\section{Conflict of interest}

The authors declare that there is no conflict of interest regarding the publication of this paper.

\section{Acknowledgements}

We thank the Highest Technological Educational Institute of Crete administration, the department Heads and all the students for their participation.

\section{References}

1. Goleman D (1998) The emotionally competent leader. Healthc Forum J 41: 36, 38, 76. [Crossref]

2. Goleman D (1995) Emotional Intelligence: Why It Can Matter More Than IQ. Bantam Books, New York

3. Mayer JD, Caruso DR, Salovey P (1999) Emotional intelligence meets traditional standards for an intelligence. Intelligence 27: 267-298.

4. Bar-On R (2000) Emotional and social intelligence: Insights from the Emotional Quotient Inventory. In R. Bar-On \& J.D.A. Parker (Eds.), The Handbook of Emotional Intelligence. John Willey \& Sons, Inc., San Francisc.

5. Petrides KV, Furnham A (2000) Gender differences in measured and self -estimated trait emotional intelligence 2000. Sex, Roles 42: 449-461.

6. Payne MS (1997) Modern Social Work Theory. London, Macmillan.

7. Oginska-Bulik N (2005) Emotional intelligence in the workplace: exploring its effects on occupational stress and health outcomes in human service workers. Int J Occup Med and Environ Heal 18: 167-175.

8. Beauvais A, Brady N, O'Shea E, Quinn, Griffin M (2011) Emotional intelligence and nursing performance among nursing students. Nurse Education Today 31: 396-401.

9. Wong CS, Law KS (2002) The effects of leader and follower emotional intelligence on performance and attitude: An exploratory study. The Leadership Quarterly.

10. Kafetsios K, Zambetakis L (2008) Emotional Intelligence and job satisfaction: Testing the mediatory role of positive and negative affect at work. Personality and Individ Differ 44: 487-500.

11. Lovibond SH, Lovibond PF (1995) Manual for the Depression Anxiety Stress Scales (2nd. Ed.) Psychology Foundation, Sydney.

12. Lyrakos GN, Arvaniti C, Smyrnioti M, Kostopanagiotou G (2011) Translation and validation study of the depression anxiety stress scale in the greek general population and in a psychiatric patient's sample. Eur Psychiatry 26: 1731.

13. Cohen S, Kamarck T, Mermelstein R (1983) A global measure of perceived stress. $J$ Health Soc Behav 24: 385-396. [Crossref]

14. Andreou E, Alexopoulos EC, Lionis C, Varvogli L, Gnardellis C, et al. (2011) Perceived Stress Scale: reliability and validity study in Greece. Int J Environ Res Public Health 8: 3287-3298. [Crossref] 
15. Mayer JD, Salovey P, Caruso DR (2000b) Emotional intelligence as zeitgeist, as personality and as a mental ability. In R. Bar- On \& J.D.A. Parker (Eds.), The Handbook of Emotional Intelligence (pp. 92-117). John Willey \& Sons, Inc., San Francisco.

16. Jeager AJ (2003) Job competencies and the curriculum: An inquiry into emotional intelligence in graduate professional education. Research in Higher Education. 44: 615-639.

17. Newsome S, Day AL, Catano VM (2000) Assessing the predictive validity of emotional intelligence. Personality and Individual Differences. 29: 1005-1016.

18. Boyatzis R, Sala F (2004) Assessing emotional intelligence competencies. In G.Geher (Ed.), The Measurement of Emotional Intelligence (pp.147-180). Novas Science Publishers, Hauppauge, NY.

19. Singh Y, Sharma R (2012) Relationship between general intelligence, emotional intelligence, stress levels and stress reactivity. Ann Neurosci 19: 107-111. [Crossref]

20. Ciarrochi JV, Chan AYC, Caputi P (2000) A critical evaluation of the emotional intelligence construct. Personality and Individual Differences 28: 539-561.
21. Schutte NS, Malouff JM, Hall LE, Haggerty DJ, Cooper JT, et al. (1998) Developmen and validation of emotional intelligence. Personality and Individ Differ 25: 167-177.

22. Collins S (2008) Statutory social workers: Stress, job satisfaction, coping, social support and individual differences. British J Soc Work 38: 1173-1193.

23. Lloyd C, King R, Chenoweth L (2002) Social work, stress and burnout: A review. $J$ Mental Heal 11: 255-265.

24. Augusto-Landa JM, Lopez-Zafra E, Berrios-Mardos MP, Aguilar-Luzon MC (2008) The relationship between emotional intelligence, occupational stress and health in nurses: A questionnaire survey. Int J of Nursing Stud 45: 888-901.

25. Rantonen O, Alexanderson K, Pentti J, Kjeldgård L, Hämäläinen J, et al. (2016) Trends in work disability with mental diagnoses among social workers in Finland and Sweden in 2005-2012. Epidemiol Psychiatr Sci. [Crossref]

26. Wagaman MA, Geiger JM, Shockley C, Segal EA (2015) The Role of Empathy in Burnout, Compassion Satisfaction, and Secondary Traumatic Stress among Social Workers. Soc Work 60: 201-209.

Copyright: @2017 Florou E. This is an open-access article distributed under the terms of the Creative Commons Attribution License, which permits unrestricted use, distribution, and reproduction in any medium, provided the original author and source are credited. 